\title{
Polyaxial stress-dependent permeability of a three-dimensional fractured rock layer
}

\author{
Qinghua Lei ${ }^{1} \cdot$ Xiaoguang Wang ${ }^{1} \cdot$ Jiansheng Xiang ${ }^{1} \cdot$ John-Paul Latham $^{1}$
}

Received: 5 December 2016 / Accepted: 16 June 2017 / Published online: 5 July 2017

(C) The Author(s) 2017. This article is an open access publication

\begin{abstract}
A study about the influence of polyaxial (true-triaxial) stresses on the permeability of a three-dimensional (3D) fractured rock layer is presented. The 3D fracture system is constructed by extruding a two-dimensional (2D) outcrop pattern of a limestone bed that exhibits a ladder structure consisting of a "through-going" joint set abutted by later-stage short fractures. Geomechanical behaviour of the 3D fractured rock in response to in-situ stresses is modelled by the finite-discrete element method, which can capture the deformation of matrix blocks, variation of stress fields, reactivation of pre-existing rough fractures and propagation of new cracks. A series of numerical simulations is designed to load the fractured rock using various polyaxial in-situ stresses and the stress-dependent flow properties are further calculated. The fractured layer tends to exhibit stronger flow localisation and higher equivalent permeability as the far-field stress ratio is increased and the stress field is rotated such that fractures are preferentially oriented for shearing. The shear dilation of pre-existing fractures has dominant effects on flow localisation in the system, while the propagation of new fractures has minor impacts. The role of the overburden stress suggests that the conventional 2D analysis that neglects the effect of the out-of-plane stress (perpendicular to the bedding interface) may provide indicative approximations but not fully capture the polyaxial stress-dependent fracture network behaviour. The results of this study have important implications for understanding the heterogeneous flow of geological fluids (e.g. groundwater, petroleum) in subsurface and upscaling permeability for largescale assessments.
\end{abstract}

Qinghua Lei

q.lei12@imperial.ac.uk

1 Department of Earth Science and Engineering, Imperial College London, London, UK
Keywords Fractured rocks $\cdot$ Stress $\cdot$ FEMDEM $\cdot$ Hydraulic properties $\cdot$ Heterogeneity

\section{Introduction}

Fractures are ubiquitous in crustal rocks in the form of faults, joints and veins, etc. These naturally occurring discontinuities often comprise complex networks and dominate hydromechanical processes in the subsurface (Zimmerman and Main 2004; Lei et al. 2017). The understanding of the nontrivial effects of natural fractures on the bulk properties of highly disordered geological media is important for many engineering applications including groundwater management, petroleum recovery, geothermal production and radioactive waste disposal (Rutqvist and Stephansson 2003).

Discrete fracture networks (DFNs) are often used to mimic naturally faulted or jointed geological systems (Dershowitz and Einstein 1988). Compared to the conventional dual porosity model (Warren and Root 1963) and analytical solution for mathematically idealised discontinuity networks (Oda 1985), the DFN approach has the advantage of explicit representation of fracture geometries together with specific description of their hydraulic transmissivities (Liu et al. 2016). The equivalent permeability tensor of a finite-sized fracture system can be derived from steady-state fluid flow simulations (Lang et al. 2014) and further used for larger-scale assessments (Blum et al. 2009). The equivalent permeability here is defined as a constant tensor in Darcy's law to represent bulk flow in a heterogeneous medium (Renard and de Marsily 1997). It is different from the notion of effective permeability that is considered as an intrinsic material property based on the existence of representative elementary volume (REV) at a large homogenisation scale. 
During the past few decades, the impact of stress on the permeability of fractured sedimentary rocks has been extensively studied based on two-dimensional (2D) fracture network models with the out-of-plane stress (perpendicular to the bedding interface) effect omitted (Zhang et al. 1996; Zhang and Sanderson 1996; Sanderson and Zhang 1999, 2004; Latham et al. 2013; Lei et al. 2014, 2015b). However, whether the effect of the out-of-plane stress is negligible may need to be examined through three-dimensional (3D) analysis. Due to the difficulties (e.g. low efficiency and meshing problem) in 3D computations, there are very few attempts to model stress-dependent fluid flow in 3D fractured rocks, an exception being a recent study by Lei et al. (2015a) which was based on an idealised 3D geometry. For more realistic fracture networks with finite-sized, non-planar discontinuities, the hydromechanical behaviour can be very different and (probably) more complex. Under in-situ stresses, finite-sized fractures aligned with the maximum principal stress direction may open and even propagate due to the high tensile stresses localised at their tips (Pollard and Segall 1987); furthermore, the sliding of pre-existing discontinuities can generate stress concentration at their ends and trigger the formation of wing/secondary cracks (Willemse and Pollard 1998). These new cracks may link pre-existing structures to form critical fluid pathways and result in an enhanced connectivity and permeability. All of these features may need to be appropriately considered in 3D simulations.

The objective of this paper is to explore the effects of polyaxial (true-triaxial) in-situ stresses on the equivalent permeability of a 3D fractured rock layer embedded with realistic joint sets. In the rest of the paper, the numerical method is briefly described, then a 3D deterministic DFN is constructed for a thin-bed limestone layer and a series of numerical experiments is designed for various polyaxial stress conditions. The simulation results about the effects of stress magnitude and orientation on the equivalent permeability of the fractured layer are presented. Finally, there is a short discussion and conclusions are drawn. This paper will mainly focus on the stress effect, whereas the complex scale effect is beyond the current scope.

\section{Numerical methods}

\section{Finite-discrete element method (FEMDEM)}

The numerical method used for geomechanical modelling is the combined finite-discrete element method (FEMDEM; Munjiza 2004). Extensive developments and applications of the FEMDEM method have been conducted in the past decade or so with different versions having emerged such as the code collaboratively developed by Queen Mary University of London (UK) and Los Alamos National Laboratory in the
USA (Munjiza et al. 2011, 2013; Rougier et al. 2014), the YGeo and Irazu by the University of Toronto, Canada (Mahabadi et al. 2012; Lisjak and Grasselli 2014; Lisjak et al. 2017), and the Solidity platform by Imperial College London (Xiang et al. 2009a, b; Guo et al. 2016; Lei 2016; Lei et al. 2016). The FEMDEM model that accommodates the finite strain elasticity coupled with a smeared crack model is able to capture the complex behaviour of fractured rocks involving deformation, displacement, rotation, interaction, fracturing and fragmentation. The principles of the 3D FEMDEM model for solving stress, deformation and interaction as well as fracture propagation are similar to those of the 2D model as presented in the literature (Latham et al. 2013; Lisjak and Grasselli 2014; Lei et al. 2016). Here, only some adaptations to 3D problems are described.

The FEMDEM model represents a 3D fractured rock using a fully discontinuous mesh of four-noded tetrahedral finite elements and six-noded joint elements. Each tetrahedral element is connected with four joint elements and each joint element is linked to two tetrahedral volumes (Fig. 1). There are two types of joint elements (Lei et al. 2016): (1) broken joint elements which are placed along existing fractures (Fig. 1a), and (2) unbroken joint elements which are embedded inside the matrix (Fig. 1b) and may transform to broken ones as new fractures propagate under stress concentration. Both broken and unbroken joint elements are used in the FEMDEM model and inserted between the facets of tetrahedral element pairs before the simulation. No remeshing is performed in later computation.

The motions of finite elements are governed by the forces acting on elemental nodes and the governing equation is given by (Munjiza 2004):

$\mathbf{M} \ddot{\mathbf{x}}+\mathbf{f}_{\text {int }}=\mathbf{f}_{\text {ext }}$

where $\mathbf{M}$ is the lumped nodal mass matrix, $\mathbf{x}$ is the vector of nodal displacements, $\mathbf{f}_{\text {int }}$ are the internal nodal forces induced by the deformation of triangular elements, $\mathbf{f}_{\text {ext }}$ are the external nodal forces including external loads $\mathbf{f}_{1}$ contributed by boundary conditions and body forces, cohesive bonding forces $\mathbf{f}_{\mathrm{b}}$ caused by the deformation of unbroken joint elements, and contact forces $\mathbf{f}_{\mathrm{c}}$ generated by the contact interaction via broken joint elements. The solid response is modelled here in the context of Terzaghi's effective stress law (i.e. the boundary load has eliminated the effect of pore pressure). The deformation of the bulk material is captured by linear-elastic constantstrain finite elements with the continuity constrained by the bonding forces of unbroken joint elements (Munjiza et al. 1999). The interaction of discrete matrix bodies is calculated based on the penetration of finite elements via broken joint elements (Munjiza and Andrews 2000). The elasto-plastic fracturing of geological rock media is modelled by a smeared crack (i.e. cohesive zone) method that can capture the non- 

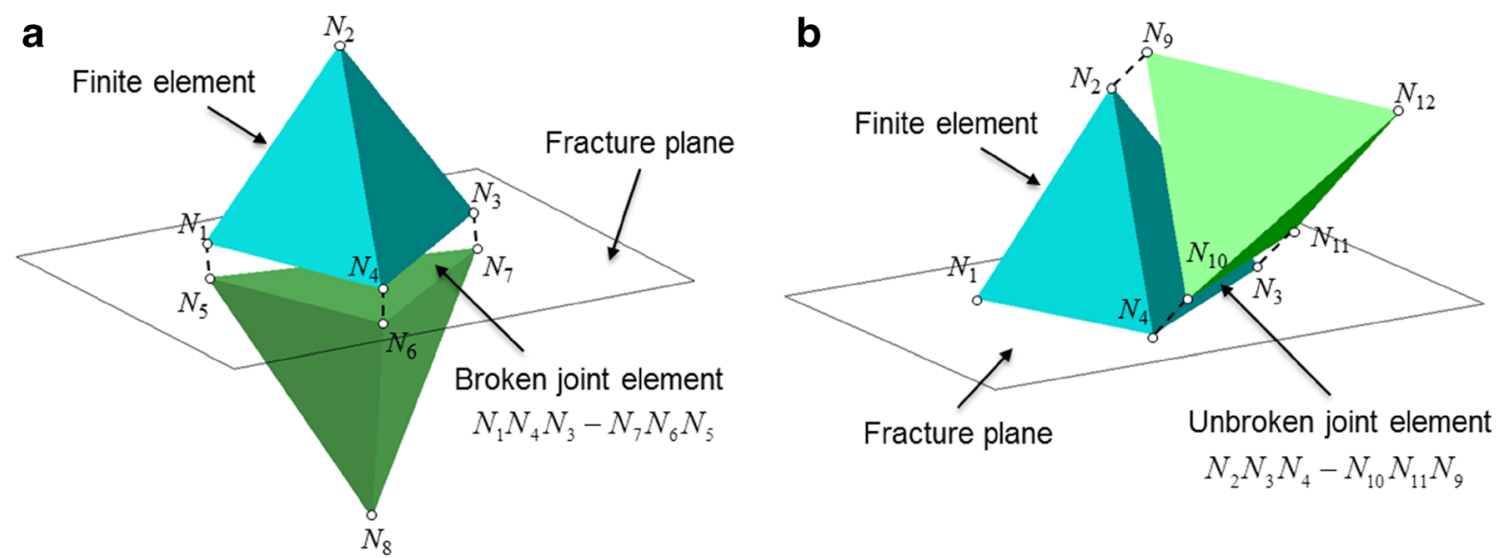

Fig. 1 Two neighbouring tetrahedral finite elements linked by $\mathbf{a}$ a broken joint element or $\mathbf{b}$ an unbroken joint element in the 3D FEMDEM model

linear stress-strain behaviour of the plastic zone ahead of a fracture tip (Munjiza et al. 1999). Such a crack propagation model has been recently implemented into the 3D FEMDEM formulation (Guo 2014; Guo et al. 2015, 2016). The equations of motion of the FEMDEM model are solved through an explicit time integration scheme based on the forward Euler method.

\section{Joint constitutive model}

A joint constitutive model (JCM), similar to the one for 2D FEMDEM (Lei et al. 2016), is implemented into the 3D FEMDEM framework to simulate the deformation of rough fractures in response to normal and/or shear loading conditions. The non-linear closure of a broken joint element under compression is characterised by an empirical hyperbolic equation (Bandis et al. 1983):

$v_{\mathrm{n}}=\frac{\sigma_{\mathrm{n}} v_{\mathrm{m}}}{k_{\mathrm{n} 0} v_{\mathrm{m}}+\sigma_{\mathrm{n}}}$

where $v_{\mathrm{n}}$ is the current normal closure (mm), $\sigma_{\mathrm{n}}$ is the local effective normal stress (MPa) that is derived from the Cauchy stress tensor of adjacent finite elements, $k_{\mathrm{n} 0}$ is the initial normal stiffness $(\mathrm{MPa} / \mathrm{mm})$, and $v_{\mathrm{m}}$ is the maximum allowable closure (mm). Values of $k_{\mathrm{n} 0}$ and $v_{\mathrm{m}}$ are given by (Bandis et al. 1983):

$k_{\mathrm{n} 0}=-7.15+1.75 \mathrm{JRC}+0.02 \times \frac{\mathrm{JCS}}{a_{0}}$

$v_{\mathrm{m}}=-0.1032-0.0074 \mathrm{JRC}+1.1350 \times\left(\frac{\mathrm{JCS}}{a_{0}}\right)^{-0.2510}$

where $a_{0}$ is the initial aperture (mm), JRC is the joint roughness coefficient, and JCS is the joint compressive strength (MPa). Coefficients derived from experimental measurements of numerous joint samples of five different rock types under a third loading cycle are adopted since in-situ fractures are considered more likely to behave in a manner similar to the third or fourth cycle (Barton et al. 1985). These empirical equations and coefficients can statistically interpret the observed behaviour of the experimental samples under the specific testing conditions (Bandis et al. 1983). However, attention may be needed if they are applied to actual engineering problems (Baghbanan and Jing 2008). Both JRC and JCS are scaledependent parameters (Bandis et al. 1981) and their fieldscale values, i.e. $\mathrm{JRC}_{\mathrm{n}}$ and $\mathrm{JCS}_{\mathrm{n}}$, can be estimated using (Barton et al. 1985):

$\mathrm{JRC}_{\mathrm{n}}=\mathrm{JRC}_{0}\left(\frac{L_{\mathrm{n}}}{L_{0}}\right)^{-0.02 \mathrm{JRC}_{0}}$

$\mathrm{JCS}_{\mathrm{n}}=\mathrm{JCS}_{0}\left(\frac{L_{\mathrm{n}}}{L_{0}}\right)^{-0.03 \mathrm{JRC}_{0}}$

where $L_{\mathrm{n}}$ is the field-scale effective joint length (i.e. size of a block edge between fracture intersections) defined by the spacing of cross-joints, $\mathrm{JRC}_{0}$ and $\mathrm{JCS}_{0}$ are measured based on the laboratory sample with length $L_{0}$.

During the shearing process under a normal compression, fractures contract first due to the compressibility of asperities and then dilate with roughness damaged and destroyed (Barton et al. 1985). Dilational displacement can be related to the shear displacement using an incremental formulation given by (Olsson and Barton 2001):

$\mathrm{d} v_{\mathrm{s}}=-\tan d_{\mathrm{mob}} \mathrm{d} u$

where $\mathrm{d} v_{\mathrm{s}}$ is the increment of normal displacement caused by shear dilation, $\mathrm{d} u$ is the increment of shear displacement, and $d_{\text {mob }}$ is the mobilised tangential dilation angle given by (Olsson and Barton 2001):

$d_{\mathrm{mob}}=\frac{1}{M} \mathrm{JRC}_{\mathrm{mob}} \log _{10}\left(\frac{\mathrm{JCS}_{\mathrm{n}}}{\sigma_{\mathrm{n}}}\right)$ 
where $M$ is a damage coefficient given by (Barton and Choubey 1977):

$M=\frac{\mathrm{JRC}_{\mathrm{n}}}{12 \log _{10}\left(\frac{\mathrm{JCS}_{\mathrm{n}}}{\sigma_{\mathrm{n}}}\right)}+0.70$

The mobilised joint roughness coefficient $\mathrm{JRC}_{\text {mob }}$ can be calculated using a dimensionless model (Barton et al. 1985) based on the ratio of the current shear displacement to the peak shear displacement $u_{\mathrm{p}}$, which is given by (Barton et al. 1985):

$u_{\mathrm{p}}=\frac{L_{\mathrm{n}}}{500}\left(\frac{\mathrm{JRC}_{\mathrm{n}}}{L_{\mathrm{n}}}\right)^{0.33}$

The coupled normal and shear deformation can thus be modelled by an incremental formulation:

$\mathrm{d} v=\mathrm{d} v_{\mathrm{n}}+\mathrm{d} v_{\mathrm{s}}$

The mechanical aperture $a_{\mathrm{m}}$ is derived by combing the effects of mesoscopic opening (induced by fracture network deformation and explicitly resolved in the FEMDEM) and microscopic closure (controlled by fracture roughness and implicitly captured by the JCM) as given by (Lei et al. 2015a, 2016):

$a_{\mathrm{m}}=\left\{\begin{array}{cc}a_{0}+w & , w \geq 0 \\ a_{0}-v & , w<0\end{array}\right.$

where $w$ is the mesoscopic normal separation of the opposite walls of broken joint elements in the deformed FEMDEM mesh, and $v$ is the microscopic accumulative closure derived from the JCM incremental calculation. The first part of the piecewise function corresponds to the scenario that the broken joint element is mesoscopically opened, while the second part models the condition that the two opposite walls of the fracture are in contact at the FEMDEM grid scale. The hydraulic aperture $a_{\mathrm{h}}$ defined as an equivalent aperture for laminar flow is derived based on an empirical relation with the mechanical aperture (Olsson and Barton 2001):

$a_{\mathrm{h}}= \begin{cases}a_{\mathrm{m}}^{2} / \mathrm{JRC}^{2.5} & , u / u_{\mathrm{p}} \leq 0.75 \\ 1 / 2 \mathrm{JRC}_{\mathrm{mob}} & , u / u_{\mathrm{p}} \geq 1.0\end{cases}$

A linear interpolation is used to determine the hydraulic aperture in the transition phase, i.e. $0.75<u / u_{\mathrm{p}}<1.0$.

\section{Fracture and matrix flow modelling}

Fluid flow through the fractured rock with multiple intersecting fractures and permeable matrix is solved using the combined finite element-finite volume method (Geiger et al. 2004). Single-phase steady state flow of incompressible fluid with constant viscosity through porous media, in absence of sources and sinks, is governed by the continuity equation and Darcy's law, which are reduced to a Laplace equation as:

$\nabla \cdot(k \nabla p)=0$

where $k$ is the intrinsic and isotropic permeability of the porous media with local variability permitted, and $p$ is the fluid pressure solved at the nodes of unstructured finite element grids by employing the standard Galerkin method. The element-wise constant barycentric velocity is resolved based on the pressure gradient vector field by applying Darcy's law given by:

$\mathbf{u}^{\mathrm{e}}=-\frac{k^{\mathrm{e}}}{\mu} \nabla p^{\mathrm{e}}$

where $\mathbf{u}^{\mathbf{e}}$ is the vector field of element-wise constant velocities, $p^{\mathrm{e}}$ is the local element pressure field, $\mu$ is the constant fluid viscosity, and $k^{\mathrm{e}}$ is the local permeability of a matrix volumetric element with an assumed constant value or a lower dimensional fracture element having a variable value related to the local hydraulic aperture $a_{\mathrm{h}}$ obeying the cubic law for laminar flow between parallel plates (Witherspoon et al. 1980). By applying a prescribed macroscopic pressure differential on each pair of opposite boundary surfaces with no-flow conditions on the remaining ones parallel to the flow direction, pressure diffusion is solved for all fracture and matrix elements of the entire domain. The equivalent permeability of the fractured media is computed using element volume weighted averaging of pressure gradients and fluxes for elements $e$ within a restricted subvolume $V$ of the flow region away from the borders to eliminate boundary effects (Lang et al. 2014):

$\frac{1}{V} \sum_{\mathrm{e}} \int_{V^{\mathrm{e}}} u_{j}^{\mathrm{e}} d V^{\mathrm{e}}=\frac{k_{i j}}{\mu} \frac{1}{V} \sum_{\mathrm{e}} \int_{V^{\mathrm{e}}} \frac{\partial p^{\mathrm{e}}}{\partial x_{i}} d V^{\mathrm{e}}$

where $u_{j}^{\mathrm{e}}$ is the element-wise barycentric velocity in the $j$ direction, $\partial p^{\mathrm{e}} / \partial x_{i}$ is the element pressure gradient along $x_{i}$, and $k_{i j}$ is the components of the symmetric second-rank permeability tensor $\mathbf{k}$ :

$\mathbf{k}=\left[\begin{array}{lll}k_{x x} & k_{x y} & k_{x z} \\ k_{y x} & k_{y y} & k_{y z} \\ k_{z x} & k_{z y} & k_{z z}\end{array}\right]$

For more details about solving the fracture and matrix flow, the reader is referred to the work by Geiger et al. (2004) and Lang et al. (2014). 


\section{Model setup}

The fracture network used in this research is based on the outcrop map of a limestone bed located at Kilve on the southern margin of the Bristol Channel Basin, UK (Fig. 2a; Belayneh and Cosgrove 2004). This fractured limestone (10 cm thick) is sandwiched between almost impervious shales and the vertically dipping joints are layer bound (not extending into the neighbouring shales). The joint network exhibits a ladder pattern consisting of two major sets. The E-W striking set (set 1) that formed in an early stage contains "through-going" (or persistent) fractures. The $\mathrm{N}-\mathrm{S}$ striking set (set 2) that developed later consists of short joints abutting the fractures of set 1 . It can be noted that this highly hierarchical joint pattern is featured by " $T$ " (i.e. abutting) and " $\mathrm{X}$ " (i.e. crossing) type nodes with only a few "I" type nodes (i.e. terminating inside matrix). Considering the very expensive runtime of 3D FEMDEM calculation, a $2 \mathrm{~m} \times 2 \mathrm{~m}$ region (Fig. 2b) is selected from the original $18 \mathrm{~m} \times 8 \mathrm{~m}$ analogue for geomechanical modelling (the selected domain requires a run-time of $\sim 220 \mathrm{~h}$ on a desktop computer equipped with an Intel(R) Xeon(R) CPU E5-2697@2.30 GHz). The extracted 2D network is extruded by $10 \mathrm{~cm}$ (i.e. the thickness of the layer) to build a 3D geometry (Fig. 2c). Material properties are assumed to represent typical fractured limestone (Lama and Vutukuri 1978; Bandis et al. 1983) as given in Table 1.

The problem domain containing pre-existing fractures is discretised by an unstructured mesh with an average element size of $\sim 3.0 \mathrm{~cm}(97,606$ tetrahedral finite elements and 201,502 triangular joint elements in total). The geomechanical behaviour of the fractured layer in response to polyaxial effective in-situ stresses is explored with respect to the variation of stress magnitude and orientation. For the study of the stress magnitude effect, the far-field stresses are loaded orthogonally to the model domain (Fig. 3a), with $\sigma_{\mathrm{x}}^{\prime}, \sigma_{\mathrm{y}}^{\prime}$ and $\sigma_{\mathrm{z}}^{\prime}$ varying between 5 and $15 \mathrm{MPa}$. For analysing the orientation effect, the polyaxial far-field stress field $\left(\sigma_{1}^{\prime}=15 \mathrm{MPa}, \sigma_{3}^{\prime}=5 \mathrm{MPa}\right.$ and $\left.\sigma_{\mathrm{z}}^{\prime}=5 \sim 15 \mathrm{MPa}\right)$ is applied at different angles $\left(\theta=30^{\circ}\right.$, $60^{\circ}, 90^{\circ}, 120^{\circ}$ and $150^{\circ}$ ) to the rock (Fig. 3b). The gravitational body forces are neglected for this thin layer. The role of pore fluid pressure is assumed to be a second-order factor for aperture development and the Biot-type poroelastic effect is only considered for a particular scenario with the Biot coefficient equal to 1.0. Single-phase steady-state fluid flow through the deformed fracture network with stress-induced variable apertures is further modelled by imposing the classical

\section{a}
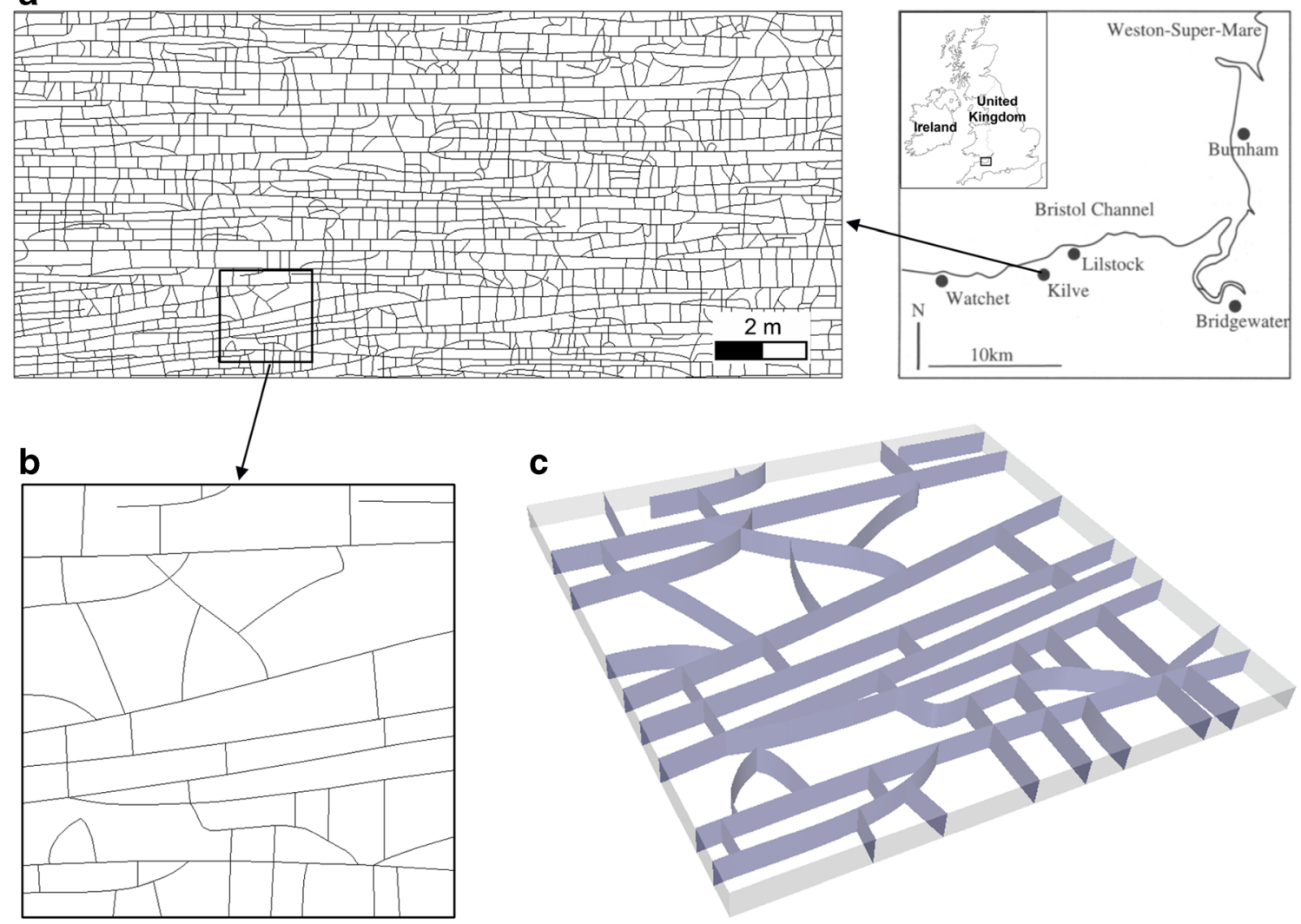

$2 m \times 2 m$

$2 \mathrm{~m} \times 2 \mathrm{~m} \times 0.1 \mathrm{~m}$

Fig. 2 a An $18 \mathrm{~m} \times 8 \mathrm{~m}$ fracture network mapped at the limestone exposure at the south margin of the Bristol Channel Basin, UK (Belayneh and Cosgrove 2004), b a $2 \mathrm{~m} \times 2 \mathrm{~m}$ region is selected and c extruded by the layer thickness (i.e. $10 \mathrm{~cm}$ ) to build the 3D geometry 
Table 1 Material properties of the fractured limestone

\begin{tabular}{ll}
\hline Property & Value \\
\hline Bulk density $\rho\left(\mathrm{kg} / \mathrm{m}^{3}\right)$ & 2,700 \\
Young's modulus $E(\mathrm{GPa})$ & 30 \\
Poisson's ratio $v$ & 0.27 \\
Tensile strength $f_{\mathrm{t}}(\mathrm{MPa})$ & 7 \\
Internal friction angle $\phi_{\mathrm{i}}\left(^{\circ}\right)$ & 26.6 \\
Cohesion $c(\mathrm{MPa})$ & 15 \\
Mode I energy release rate $G_{\mathrm{I}}\left(\mathrm{J} / \mathrm{m}^{2}\right)$ & 100 \\
Mode II energy release rate $G_{\mathrm{II}}\left(\mathrm{J} / \mathrm{m}^{2}\right)$ & 400 \\
Matrix permeability $k_{\mathrm{m}}\left(\mathrm{m}^{2}\right)$ & $1 \times 10^{-15}$ \\
Residual friction angle $\phi_{\mathrm{r}}\left({ }^{\circ}\right)$ & 31 \\
Laboratory sample length $L_{0}(\mathrm{~m})$ & 0.2 \\
$\mathrm{JCS}_{0}(\mathrm{MPa})$ & 169 \\
$\mathrm{JRC}_{0}$ & 9.7 \\
Initial mechanical aperture $a_{0}(\mathrm{~mm})$ & 0.194 \\
\hline
\end{tabular}

permeameter boundary condition: two opposite boundary surfaces of the rectangular volume domain have a fixed pressure drop (i.e. $1 \mathrm{kPa}$ ), while the four orthogonal boundaries parallel to the flow direction are impervious (Fig. 3c). Matrix permeability $k_{\mathrm{m}}$ is assumed to be $1 \times 10^{-15} \mathrm{~m}^{2}$, which gives a high fracture-matrix permeability contrast so that the flow is dominated by fractures (Matthäi and Belayneh 2004). To analyse the distribution of vertical flow under the prescribed vertical pressure drop, a $20 \times 20$ square grid is superimposed over the finite element system. The flow rate of each square area is computed by summing the fluxes of the finite element nodes inside the local square. This approach provides a way to characterise and visualise the heterogeneous distribution of vertical flow through the fractured rock layer (Sanderson and Zhang 1999).

\section{Results}

\section{Effect of stress magnitude}

Figure 4 presents the simulation results with different $\sigma_{x}^{\prime}$ ranging from 5 to $15 \mathrm{MPa}$, but the same $\sigma_{\mathrm{y}}^{\prime}=5 \mathrm{MPa}$ and $\sigma_{\mathrm{z}}^{\prime}=10 \mathrm{MPa}$. With the increase of $\sigma_{\mathrm{x}}^{\prime}$, the distribution of local maximum principal stresses in the rock changed from a homogeneous pattern to a highly heterogeneous field with the high stress zones aligning the direction of $\sigma_{\mathrm{x}}^{\prime}$ (Fig. 4a). The increased horizontal stress ratio of $\sigma_{\mathrm{x}}^{\prime} / \sigma_{\mathrm{y}}^{\prime}$ also triggered the sliding of pre-existing fractures (especially the persistent ones; Fig. 4b), which accommodated large apertures, caused slight crack propagation (Fig. 4c) and formed highly localised channels for vertical flow (Fig. 4d). The presence of flow in the squares with no fractures (see green cubes in Fig. 4d) is attributed to the nonzero matrix permeability. As shown in Fig. 4d, fluid is predominantly transported through the zones with preexisting fractures and flow localisation under the increased horizontal stress ratio tends to be mainly induced by the shear dilation of pre-existing fractures.
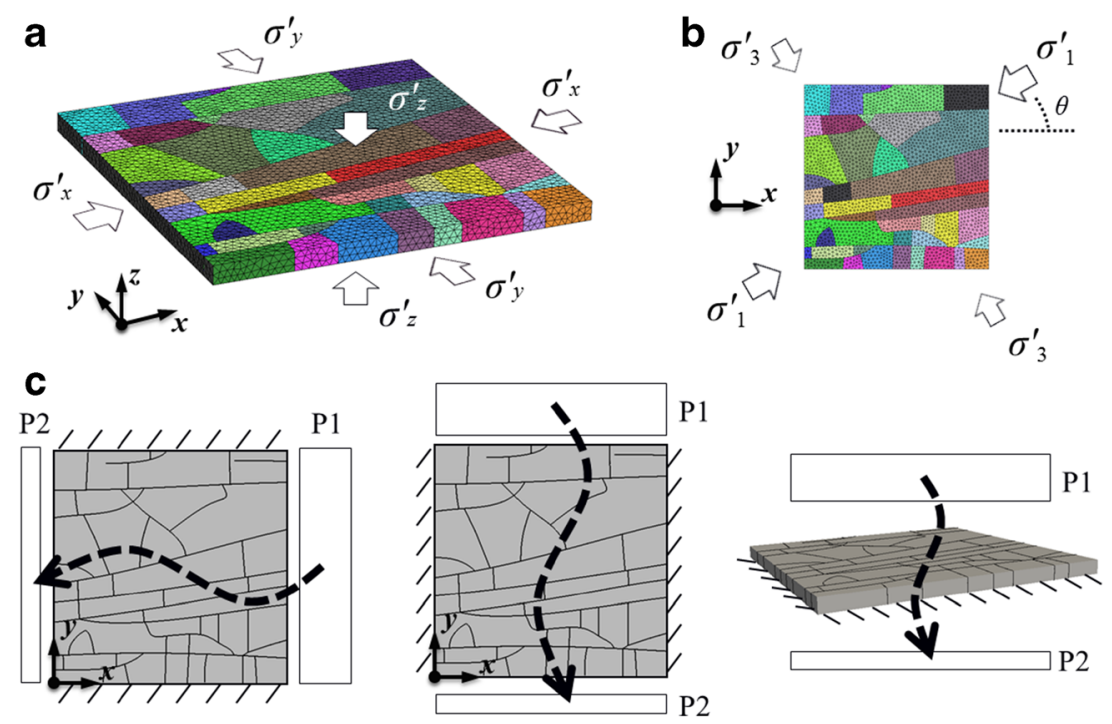

Fig. 3 Procedure for the numerical experiment: geomechanical modelling with polyaxial effective stresses applied $\mathbf{a}$ orthogonally and $\mathbf{b}$ obliquely to the problem domain, and $\mathbf{c}$ calculation of the equivalent permeability based on single-phase steady-state fluid flow through the stressed layer under a prescribed macroscopic pressure differential imposed on each pair of opposite boundaries, while the remaining ones are impervious $\left(\sigma_{x}^{\prime}, \sigma_{y}^{\prime}\right.$ and $\sigma_{z}^{\prime}$ denote the far-field stress components in the $\mathrm{x}, \mathrm{y}$ and $\mathrm{z}$ directions, respectively; $\sigma_{1}^{\prime}$ and $\sigma_{3}^{\prime}$ denote the maximum and minimum far-field principal stresses, respectively; $\theta$ indicates the angle of rotation of the far-field stress field with respect to the $\mathrm{z}$ axis; $P 1-P 2$ gives the fluid pressure drop across the rock) 
$\sigma_{\mathrm{x}}^{\prime}=5 \mathrm{MPa}, \sigma_{\mathrm{y}}^{\prime}=5 \mathrm{MPa}, \sigma_{\mathrm{z}}^{\prime}=10 \mathrm{MPa}$ :
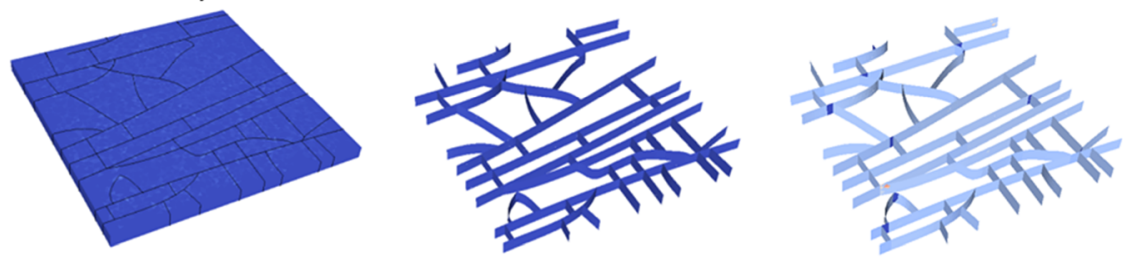

$\sigma_{\mathrm{x}}^{\prime}=10 \mathrm{MPa}, \sigma_{\mathrm{y}}^{\prime}=5 \mathrm{MPa}, \sigma_{\mathrm{z}}^{\prime}=10 \mathrm{MPa}:$
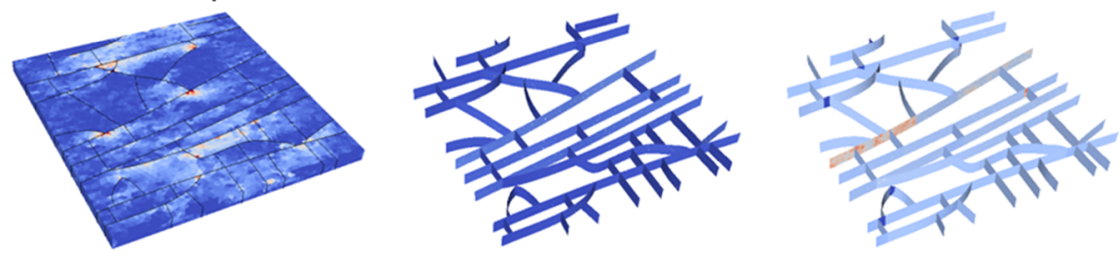

$\sigma_{\mathrm{x}}^{\prime}=15 \mathrm{MPa}, \sigma_{\mathrm{y}}^{\prime}=5 \mathrm{MPa}, \sigma_{\mathrm{z}}^{\prime}=10 \mathrm{MPa}:$
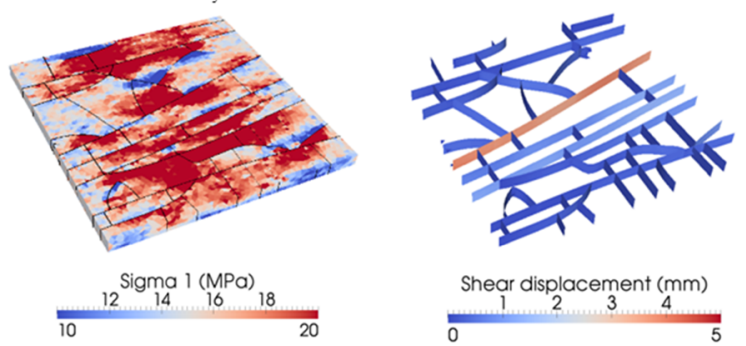

a

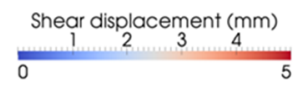

b
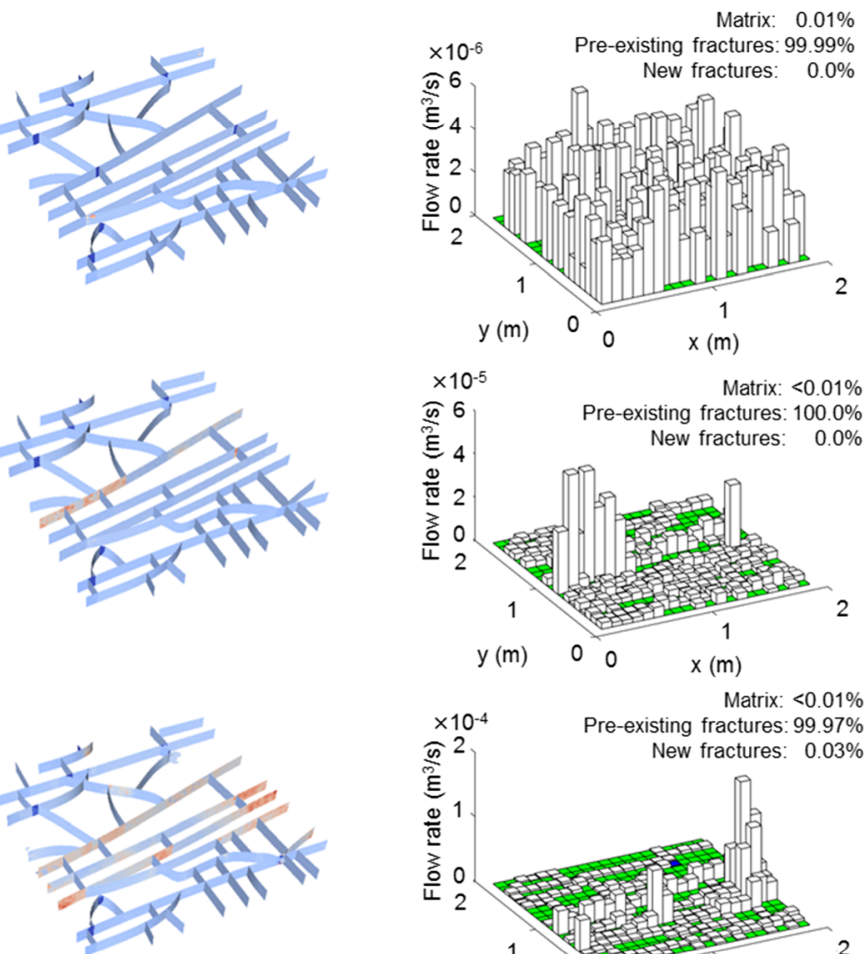

Hydraulic aperture $(\mathrm{mm})$
0.02
0.1

C

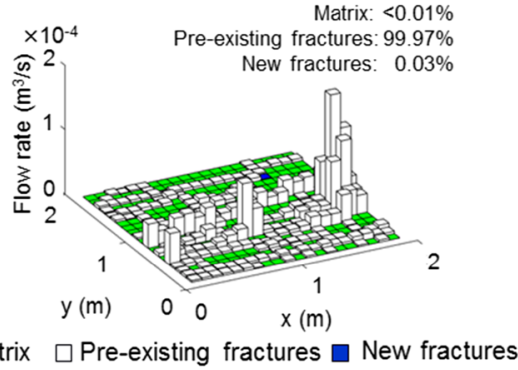

d

Fig. 4 Distributions of a local maximum principal stresses, $b$ shear displacements, $\mathbf{c}$ hydraulic apertures and $\mathbf{d}$ vertical flow rates (under a prescribed vertical pressure drop of $1 \mathrm{kPa}$ ) in the fractured layer under polyaxial stress conditions with a varied $\sigma_{x}^{\prime}=5,10$, or $15 \mathrm{MPa}$ and fixed

$\sigma_{y}^{\prime}=5 \mathrm{MPa}, \sigma_{z}^{\prime}=10 \mathrm{MPa}$. Note that in $\mathbf{d}$, cubes with different colours, i.e. green, white and blue, correspond to the flow through matrix, preexisting fractures and new fractures, respectively, and the flow rate axis scales differently in different cases

Simulations were conducted for all combinations of $\sigma_{\mathrm{x}}^{\prime}$, $\sigma_{y}^{\prime}, \sigma_{z}^{\prime}=5,10$ or $15 \mathrm{MPa}$ (i.e. 27 stress scenarios) and the stress-dependent equivalent permeability is presented in Fig. 5. The bed-normal permeability, i.e. $k_{\mathrm{zz}}$, of the fractured layer is about one order of magnitude larger than the horizontal components, i.e. $k_{\mathrm{xx}}$ and $k_{\mathrm{yy}}$. Note that $k_{\mathrm{xx}}$ is larger than $k_{y y}$ due to the better connectivity of the joint pattern in the $\mathrm{x}$ direction, i.e. the strike direction of the dominant persistent fractures. It can be noticed that the variation of the equivalent permeability exhibits distinct behaviour in the $\mathrm{x}$ and $\mathrm{y}$ directions. The equivalent permeability is much more sensitive to an increased $\sigma_{\mathrm{x}}^{\prime} / \sigma_{\mathrm{y}}^{\prime}$ than to an increased $\sigma_{\mathrm{y}}^{\prime} / \sigma_{\mathrm{x}}^{\prime}$, due to the geometrical anisotropy of the joint network. $k_{z z}$ also seems to be more sensitive to the stress variation than $k_{\mathrm{xx}}$ and $k_{\mathrm{yy}}$. It can be seen that the permeability contrast of $k_{\mathrm{zz}} / k_{\mathrm{yy}}$ spans over almost two orders of magnitude when $\sigma_{\mathrm{x}}^{\prime} /$ $\sigma_{\mathrm{y}}^{\prime}=3$; furthermore, an increased vertical stress $\sigma_{\mathrm{z}}^{\prime}$ seems to reduce the equivalent permeability, which may be attributed to the more closed apertures under higher mean stresses. The results demonstrate that the magnitude and ratio of the farfield stresses have important impact on the permeability of the fractured layer.

\section{Effect of stress orientation}

Figure 6 compares the simulation results of rotating a polyaxial far-field stress field $\left(\sigma_{1}^{\prime}=15 \mathrm{MPa}, \sigma_{3}^{\prime}=5 \mathrm{MPa}\right.$ and $\sigma_{\mathrm{z}}^{\prime}=10 \mathrm{MPa}$ ) by a range of angles $\theta$ with the $\mathrm{z}$ direction as the axis of rotation. Note $\theta=0^{\circ}$ corresponds the case of $\sigma_{\mathrm{x}}^{\prime}=15 \mathrm{MPa}, \sigma_{\mathrm{y}}^{\prime}=5 \mathrm{MPa}$ and $\sigma_{\mathrm{z}}^{\prime}=10 \mathrm{MPa}$ as has been shown in Fig. 4. The spatial distribution of local maximum principal stresses varies according to the stress field rotation, with the high stress bands formed along the direction of $\sigma_{1}^{\prime}$ (Fig. 6a). Compared to the cases with orthogonally loaded stresses (i.e. $\theta=0^{\circ}$ and $90^{\circ}$ ), the fracture sets under oblique stress fields are more preferentially oriented for shearing with wider hydraulic apertures (caused by shear dilation and block rotation), more new cracks and stronger flow localisation generated (Fig. 6b,c,d). This is further confirmed by Fig. 7 (see the solid lines), which shows the variation of the average shear displacement, average hydraulic aperture and length of new cracks of the fracture network in response to the change of the stress orientation. The fracture network in the $30^{\circ}$ and $150^{\circ}$ cases experienced the most intensive shearing; fractures in the $30^{\circ}, 60^{\circ}$ and $150^{\circ}$ cases are 
Fig. 5 Variation of the equivalent permeability components a $k_{\mathrm{xx}}, \mathbf{b}$ $k_{\mathrm{yy}}$, and $\mathbf{c} k_{\mathrm{zz}}$ of the fractured rock layer under various polyaxial stress conditions $\left(\sigma_{\mathrm{x}}^{\prime}, \sigma_{\mathrm{y}}^{\prime}, \sigma_{\mathrm{z}}^{\prime}=5\right.$, 10 or $15 \mathrm{MPa}$, i.e. 27 stress scenarios)
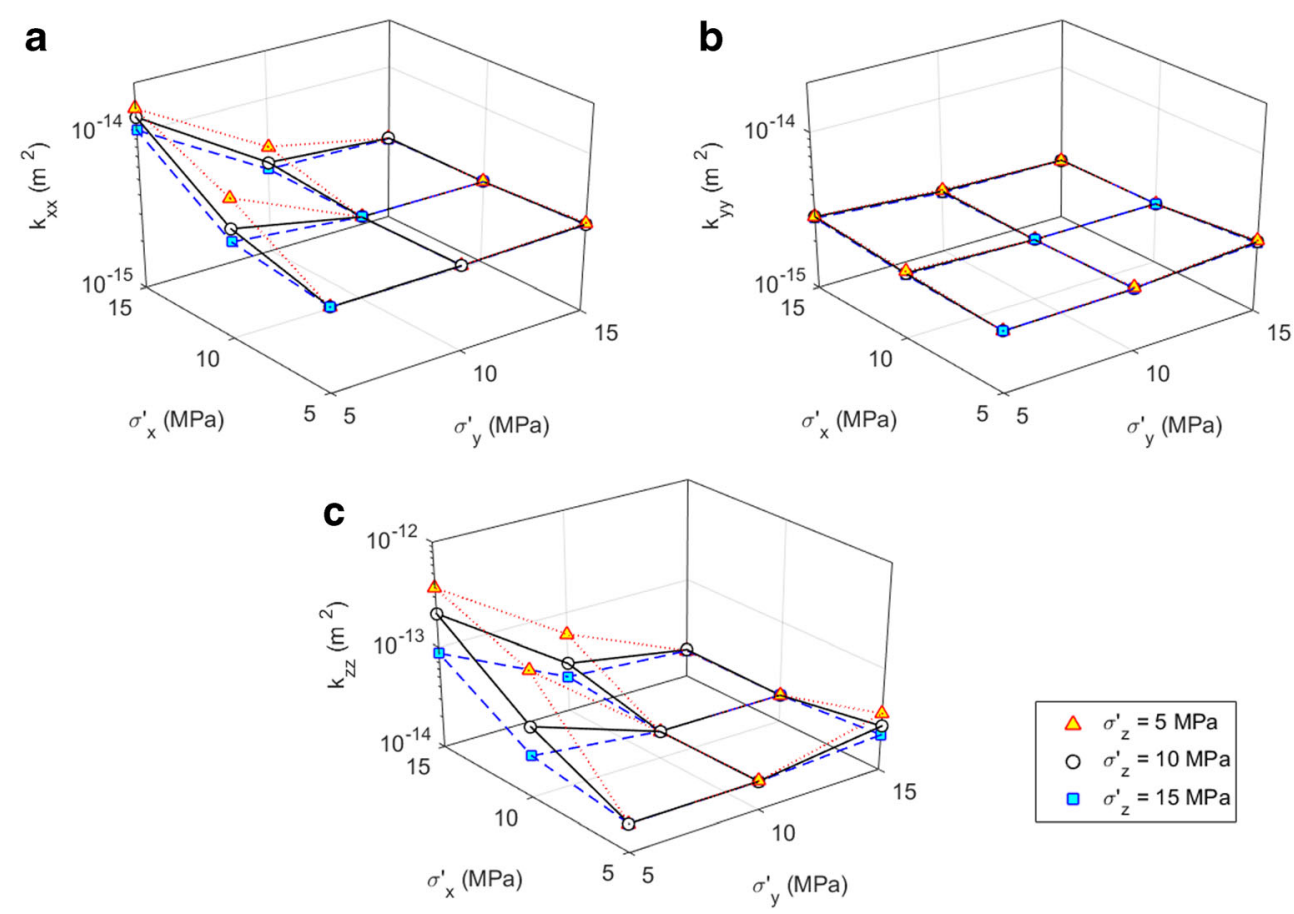

associated with the larger hydraulic apertures; new cracks propagated most in the $60^{\circ}$ case; thus, the fractured layer exhibited much higher permeability under obliquely loaded far-field stresses (Fig. 8). As shown in Fig. 6d, the flow localisation is also dominated by the shear dilation of preexisting fractures (contributing to $>90 \%$ of the total flow), while the propagation of new fractures has minor impacts (contributing to $<10 \%$ of the total flow).

The vertical stress $\sigma_{z}^{\prime}$ seems to have some important influence on fracture and flow behaviour. The polyaxial stress condition with $\sigma_{\mathrm{z}}^{\prime}=10 \mathrm{MPa}$ tends to trigger more sliding on fracture walls (Fig. 7a), which may be explained by the relation of $\sigma_{3}^{\prime}<\sigma_{z}^{\prime}<\sigma_{1}^{\prime}$ that concentrates differential stresses to develop horizontally, whereas in other cases $\sigma_{\mathrm{z}}^{\prime}$ is either equal to $\sigma_{1}^{\prime}$ or $\sigma_{3}^{\prime}$. An increased $\sigma_{\mathrm{z}}^{\prime}$ tends to enhance the compression of fracture walls (due to increased mean stresses) and therefore reduces fracture apertures (Fig. 7b). Furthermore, more new cracks emerged in the cases of $\sigma_{z}^{\prime}=5$ and $15 \mathrm{MPa}$ (Fig. $7 \mathrm{c}$ ), because such stress conditions tend to assist the propagation either horizontally along the direction of $\sigma^{\prime}{ }_{1}$ (when $\sigma_{\mathrm{z}}^{\prime}=5 \mathrm{MPa}$ ) or vertically through the layer thickness (when $\sigma_{z}^{\prime}=15 \mathrm{MPa}$ ). The role of the overburden stress in fracture shearing, aperture change and crack propagation resulted in a complex phenomenon that the increased $\sigma_{z}^{\prime}$ can lead to either increased or decreased permeability in different orientation scenarios (Fig. 8). It is noted that $\sigma_{\mathrm{z}}^{\prime}$ has negligible influence on $k_{\mathrm{xx}}$ and $k_{\mathrm{yy}}$, but can significantly affect $k_{\mathrm{zz}}$ (although the variation is within one order of magnitude).

\section{Discussion}

Stress-controlled variability of fracture displacements and apertures in a 3D fractured sedimentary layer embedded with realistic joint sets has been simulated using the 3D FEMDEM model. The behaviour of fractures such as shearing, opening and propagating is significantly influenced by the magnitude and orientation of the polyaxial stress field. When pre-existing fractures are preferentially oriented to the far-field stresses associated with a high stress ratio, considerable shearing would occur and further trigger the rotation of matrix blocks, with some very large openings created (along block boundaries) and strongly heterogeneous fluid flows induced. The simulation results show consistency with previous field observations: only a small portion of fractures are highly conductive (Tsang and Neretnieks 1998; Follin et al. 2014); critically stressed faults tend to have much higher hydraulic conductivity (Barton et al. 1995; Zoback 2007). The observation that the shear dilation of preexisting fractures has dominant effects on flow localisation based on our simulations is also consistent with the results of previous numerical studies (Min et al. 2004; Baghbanan and Jing 2008; Zhao et al. 2011). Compared to the results based on an idealised 3D persistent fracture network (Lei et al. 2015a), the permeability of this fractured layer is less sensitive to stress changes, because the matrix blocks of this limestone layer are partially bounded by impersistent fractures and tend to be more difficult to rotate under more restrictive interlocking between blocks. Furthermore, the important role of the out-of-plane stress (perpendicular to the 

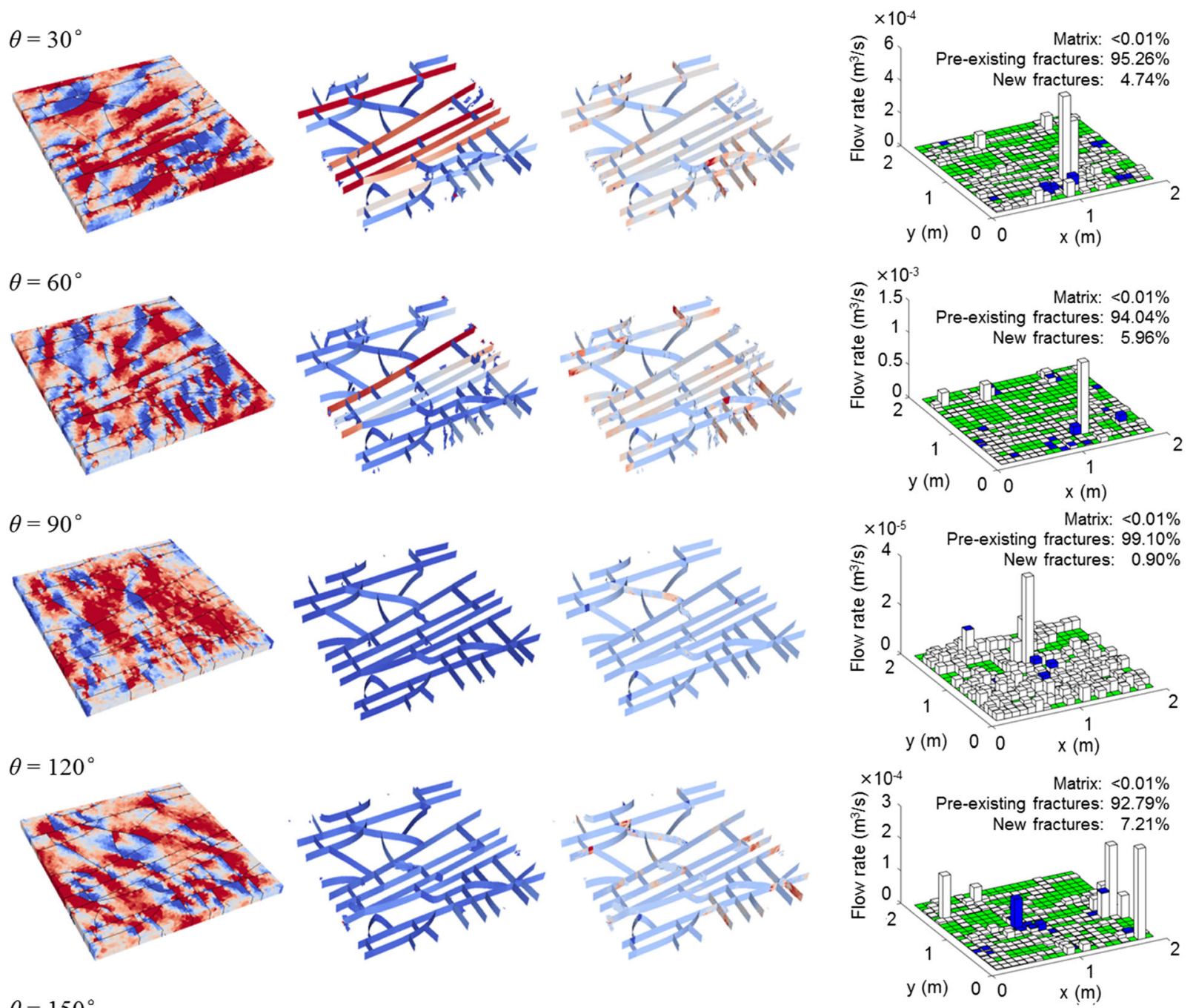
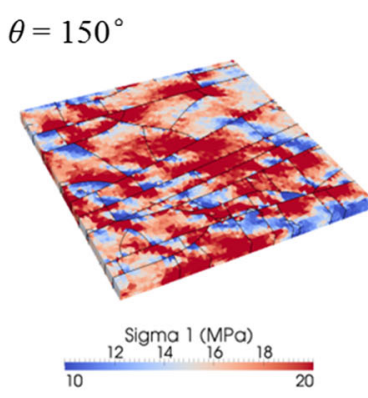

a
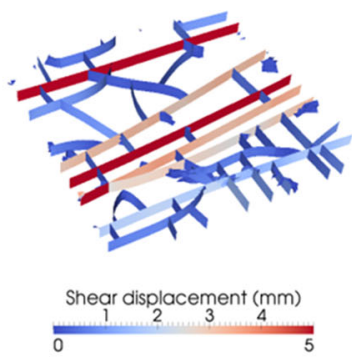

b

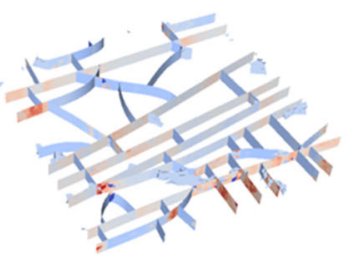

Hydraulic aperture (mm)

C

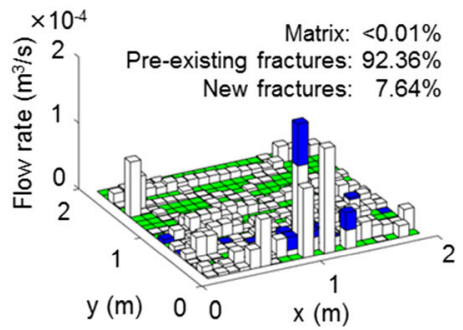

$\square$ Matrix $\square$ Pre-existing fractures $\square$ New fractures

d

Fig. 6 Distributions of a local maximum principal stresses, b shear displacements, $\mathbf{c}$ hydraulic apertures and $\mathbf{d}$ vertical flow rates (under a prescribed vertical pressure gradient of $1 \mathrm{kPa}$ ) in the fractured layer under the polyaxial stresses of $\sigma_{1}^{\prime}=15 \mathrm{MPa}, \sigma_{3}^{\prime}=5 \mathrm{MPa}, \sigma_{\mathrm{z}}^{\prime}=10 \mathrm{MPa}$ applied

bedding interface) inferred from the simulation results (Figs. 5, 7 and 8) suggests that 2D models (Zhang et al. 1996; Zhang and Sanderson 1996; Sanderson and Zhang 1999, 2004; Latham et al. 2013; Lei et al. 2014) may provide indicative approximations but not fully capture the polyaxial stress-dependent behaviour of 3D fractured layers, which requires $3 \mathrm{D}$ modelling. at different angles. Note that in $\mathbf{d}$, cubes with different colours, i.e. green, white and blue, correspond to the flow through matrix, pre-existing fractures and new fractures, respectively, and the flow rate axis scales differently in different cases

Despite the great capability of the 3D model developed, some limitations may still exist - for example, the fracture behaviour was modelled based on an empirical formulation that assumes isotropic roughness properties; however, both laboratory and numerical experiments have shown that fracture apertures evolve anisotropically under shearing and form more pronounced channels perpendicular to the shear direction (Yeo 

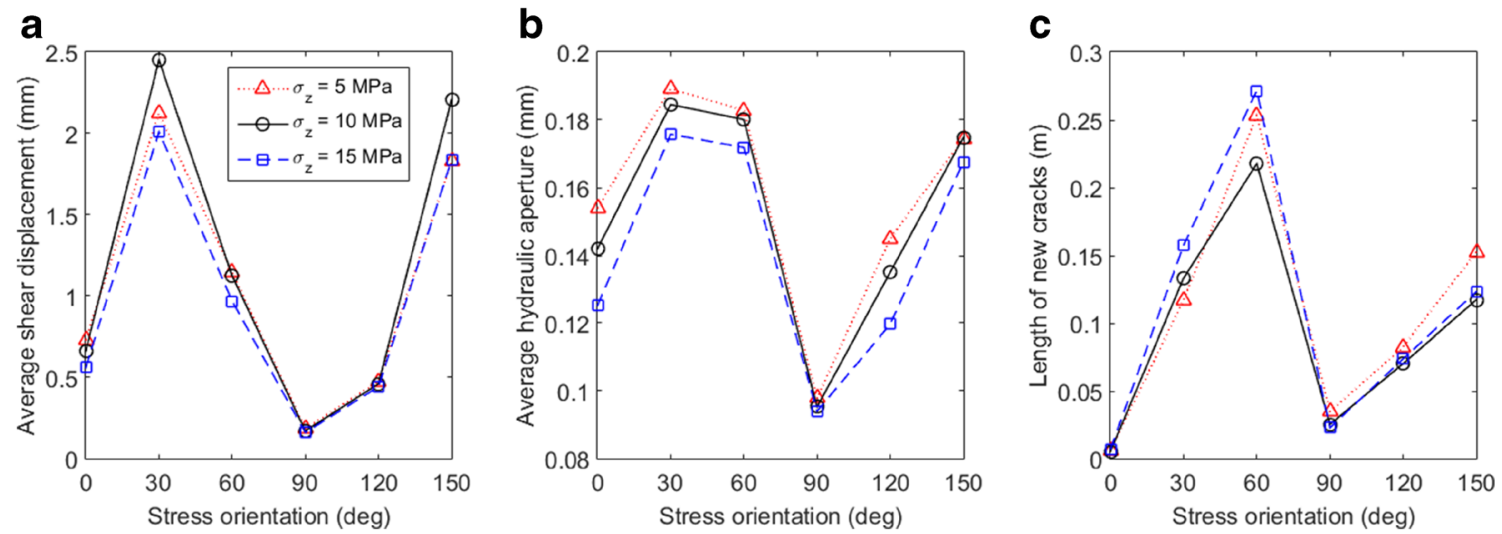

Fig. 7 Variation of a the average shear displacement, $\mathbf{b}$ average hydraulic aperture, and $\mathbf{c}$ length of new cracks with the orientation change of the polyaxial far-field stress fields with $\sigma_{1}^{\prime}=15 \mathrm{MPa}, \sigma_{3}^{\prime}=5 \mathrm{MPa}, \sigma_{z}^{\prime}=5,10$ or $15 \mathrm{MPa}$

et al. 1998; Koyama et al. 2006). Such an anisotropic effect may lead to even higher bed-normal permeability and more localised vertical flow in the fractured layer. To simulate it, a 3D anisotropic joint constitutive model, e.g. the one proposed by Jing et al. (1994), would need to be implemented into the 3D FEMDEM framework. Another limitation is that initial apertures were assumed constant for the whole joint network. The important correlation between fracture apertures and fracture sizes may be modelled using a linear (Pollard and Segall 1987) or sublinear (Olson 2003) correlation, while the intrinsic heterogeneity of fracture wall asperities may be further modelled by fractal (Thompson and Brown 1991) or selfaffine (Oron and Berkowitz 1998) profiles. The complex relation between mechanical and hydraulic apertures of rough fractures can also have important influences on the fluid flow behaviour (Luo et al. 2016); furthermore, due to the very expensive run-time of the 3D FEMDEM calculation based on the current processing power, the modelling domain is limited to metric scale. To compute larger-scale problems, parallelisation techniques may be employed in the FEMDEM computation (Lukas et al. 2014). In addition, the method of upscaling small-scale modelling results with statistical and geomechanical properties preserved (Lei et al. 2015b) can also be a possible solution. Extensions of this 3D work also include hydromechanical modelling of a fractured multilayer system, such as the one constructed in Wang et al. (2017), where the fluid flow in bedding planes is also stress-dependent and can influence the vertical flow through the layers. One more avenue for future work is the analysis of more general 3D fracture networks with randomly oriented fractures, which are more indicative of crystalline rocks; however, the difficulty of meshing such complex geometries involving very small intersection angles needs to be tackled.

\section{Conclusions}

To conclude, this paper presented a study of the stress, deformation and fluid flow in a 3D fractured rock layer embedded with a realistic joint network under various polyaxial stress conditions. Geomechanical behaviour of the fractured layer was simulated by the 3D FEMDEM model combined with a
Fig. 8 Variation of the equivalent permeability of the fracture layer with the orientation change of the polyaxial far-field stress fields with $\sigma_{1}{ }_{1}=15 \mathrm{MPa}, \sigma_{3}{ }_{3}=5 \mathrm{MPa}$, $\sigma_{z}^{\prime}=5,10$ or $15 \mathrm{MPa}$

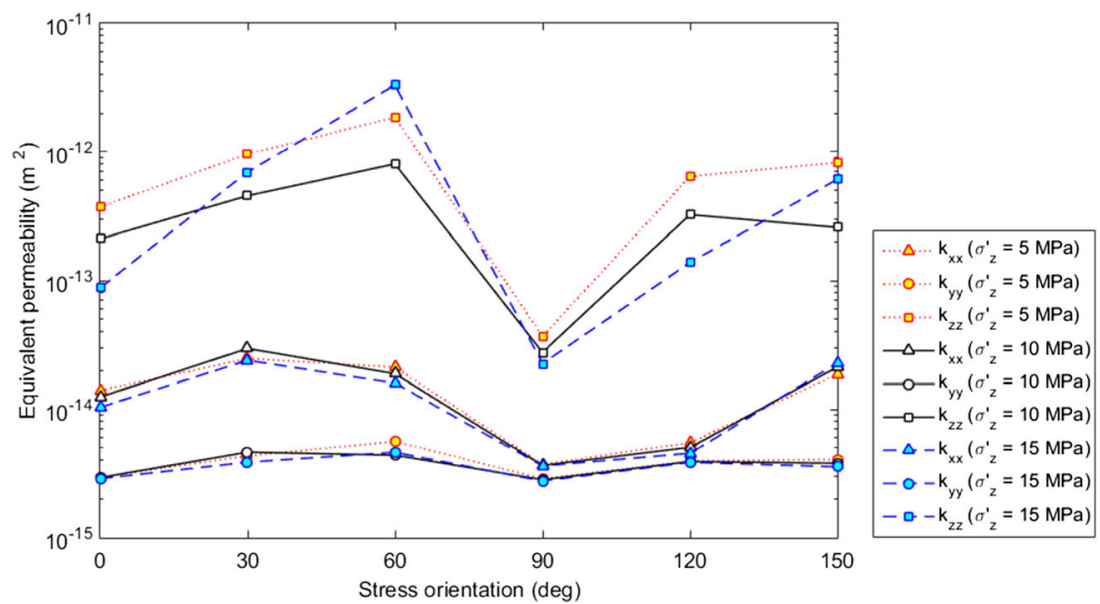


joint constitutive model and a crack propagation model. Important rock and fracture responses have been captured including the normal/shear deformation of pre-existing fractures and the propagation of new fractures. The polyaxial stress field with a high stress ratio and/or an oblique orientation to fracture sets can result in strongly heterogeneous distributions of stresses, shear displacements and fracture apertures. The fractured layer also tends to exhibit stronger flow localisation and higher equivalent permeability as the far-field stress ratio is increased and the stress field is rotated such that fractures are preferentially oriented for shearing. The shear dilation of pre-existing fractures has dominant effects on flow localisation in the system, while the propagation of new fractures has minor impacts. The role of the overburden stress suggests that the conventional $2 \mathrm{D}$ analysis that neglects the out-of-plane stress effect may provide indicative approximations but not fully capture the polyaxial stress-dependent behaviour of 3D fractured layers. The results of this study have important implications for upscaling permeability to grid block properties for reservoir flow simulation and exploring mineral deposits for the mining industry.

Acknowledgements The first author would like to acknowledge the Janet Watson scholarship awarded by the Department of Earth Science and Engineering, Imperial College London. The authors are grateful to the Natural Environment Research Council (NERC) for the support under Grant NE/L000660/1. The Fraunhofer Institute for Algorithms and Scientific Computing is acknowledged for providing a licence of the SAMG (Algebraic Multigrid Methods for Systems) solver for this research.

Open Access This article is distributed under the terms of the Creative Commons Attribution 4.0 International License (http:// creativecommons.org/licenses/by/4.0/), which permits unrestricted use, distribution, and reproduction in any medium, provided you give appropriate credit to the original author(s) and the source, provide a link to the Creative Commons license, and indicate if changes were made.

\section{References}

Baghbanan A, Jing L (2008) Stress effects on permeability in a fractured rock mass with correlated fracture length and aperture. Int J Rock Mech Min Sci 45:1320-1334. doi:10.1016/j.jirmms.2008.01.015

Bandis S, Lumsden AC, Barton NR (1981) Experimental studies of scale effects on the shear behaviour of rock joints. Int J Rock Mech Min Sci Geomech Abstr 18:1-21. doi:10.1016/0148-9062(81)90262-X

Bandis SC, Lumsden AC, Barton NR (1983) Fundamentals of rock joint deformation. Int J Rock Mech Min Sci Geomech Abstr 20:249-268. doi:10.1016/0148-9062(83)90595-8

Barton N, Choubey V (1977) The shear strength of rock joints in theory and practice. Rock Mech 10:1-54. doi:10.1007/BF01261801

Barton N, Bandis S, Bakhtar K (1985) Strength, deformation and conductivity coupling of rock joints. Int J Rock Mech Min Sci Geomech Abstr 22:121-140. doi:10.1016/0148-9062(85)93227-9

Barton CA, Zoback MD, Moos D (1995) Fluid flow along potentially active faults in crystalline rock. Geology 23:683-686. doi:10.1130/ 0091-7613(1995)023<0683:FFAPAF>2.3.CO;2
Belayneh M, Cosgrove JW (2004) Fracture-pattern variations around a major fold and their implications regarding fracture prediction using limited data: an example from the Bristol Channel Basin. In: Cosgrove JW, Engelder T (eds) The initiation, propagation, and arrest of joints and other fractures. Geol Soc Spec Pub Lond 231: 89-102

Blum P, Mackay R, Riley MS (2009) Stochastic simulations of regional scale advective transport in fractured rock masses using block upscaled hydro-mechanical rock property data. J Hydrol 369:318325. doi:10.1016/j.jhydrol.2009.02.009

Dershowitz WS, Einstein HH (1988) Characterizing rock joint geometry with joint system models. Rock Mech Rock Eng 21:21-51. doi:10. 1007/BF01019674

Follin S, Hartley L, Rhén I, Jackson P, Joyce S, Roberts D, Swift B (2014) A methodology to constrain the parameters of a hydrogeological discrete fracture network model for sparsely fractured crystalline rock, exemplified by data from the proposed high-level nuclear waste repository site at Forsmark, Sweden. Hydrogeol J 22:313331. doi:10.1007/s10040-013-1080-2

Geiger S, Roberts S, Matthäi SK, Zoppou C, Burri A (2004) Combining finite element and finite volume methods for efficient multiphase flow simulations in highly heterogeneous and structurally complex geologic media. Geofluids 4:284-299. doi:10.1111/j.1468-8123. 2004.00093.x

Guo L (2014) Development of a three-dimensional fracture model for the combined finite-discrete element method. PhD Thesis, Imperial College London, London

Guo L, Latham J-P, Xiang J (2015) Numerical simulation of breakages of concrete armour units using a three-dimensional fracture model in the context of the combined finite-discrete element method. Comput Struct 146:117-142. doi:10.1016/j.compstruc.2014.09.001

Guo L, Xiang J, Latham J-P, Izzuddin B (2016) A numerical investigation of mesh sensitivity for a new three-dimensional fracture model within the combined finite-discrete element method. Eng Fract Mech 151:70-91. doi:10.1016/j.engfracmech.2015.11.006

Jing L, Nordlund E, Stephansson O (1994) A 3-D constitutive model for rock joints with anisotropic friction and stress dependency in shear stiffness. Int J Rock Mech Min Sci Geomech Abstr 31:173-178. doi: 10.1016/0148-9062(94)92808-8

Koyama T, Fardin N, Jing L, Stephansson O (2006) Numerical simulation of shear-induced flow anisotropy and scale-dependent aperture and transmissivity evolution of rock fracture replicas. Int J Rock Mech Min Sci 43:89-106. doi:10.1016/j.ijrmms.2005.04.006

Lama RD, Vutukuri VS (1978) Handbook on mechanical properties of rocks: testing techniques and results, vol 2. Trans. Tech., Clausthal, Germany

Lang PS, Paluszny A, Zimmerman RW (2014) Permeability tensor of three-dimensional fractured porous rock and a comparison to trace map predictions. J Geophys Res Solid Earth 119:6288-6307. doi: 10.1002/2014JB011027

Latham J-P, Xiang J, Belayneh M, Nick HM, Tsang C-F, Blunt MJ (2013) Modelling stress-dependent permeability in fractured rock including effects of propagating and bending fractures. Int J Rock Mech Min Sci 57:100-112. doi:10.1016/j.ijrmms.2012.08.002

Lei Q (2016) Characterisation and modelling of natural fracture networks: geometry, geomechanics and fluid flow. PhD Thesis, Imperial College London, London

Lei Q, Latham J-P, Xiang J, Tsang C-F, Lang P, Guo L (2014) Effects of geomechanical changes on the validity of a discrete fracture network representation of a realistic two-dimensional fractured rock. Int J Rock Mech Min Sci 70:507-523. doi:10.1016/j.ijrmms.2014.06.001

Lei Q, Latham J, Xiang J, Tsang C (2015a) Polyaxial stress-induced variable aperture model for persistent 3D fracture networks. Geomech Energy Environ 1:34-47. doi:10.1016/j.gete.2015.03.003

Lei Q, Latham J-P, Tsang C-F, Xiang J, Lang P (2015b) A new approach to upscaling fracture network models while preserving geostatistical 
and geomechanical characteristics. J Geophys Res Solid Earth 120: 4784-4807. doi:10.1002/2014JB011736

Lei Q, Latham J-P, Xiang J (2016) Implementation of an empirical joint constitutive model into finite-discrete element analysis of the geomechanical behaviour of fractured rocks. Rock Mech Rock Eng 49:4799-4816. doi:10.1007/s00603-016-1064-3

Lei Q, Latham J, Tsang C (2017) The use of discrete fracture networks for modelling coupled geomechanical and hydrological behaviour of fractured rocks. Comput Geotech 85:151-176. doi:10.1016/j. compgeo.2016.12.024

Lisjak A, Grasselli G (2014) A review of discrete modeling techniques for fracturing processes in discontinuous rock masses. J Rock Mech Geotech Eng 6:301-314. doi:10.1016/j.jrmge.2013.12.007

Lisjak A, Kaifosh P, He L, Tatone BSA, Mahabadi OK, Grasselli G (2017) A 2D, fully-coupled, hydro-mechanical, FDEM formulation for modelling fracturing processes in discontinuous, porous rock masses. Comput Geotech 81:1-18. doi:10.1016/j.compgeo.2016.07.009

Liu R, Li B, Jiang Y, Huang N (2016) Review: mathematical expressions for estimating equivalent permeability of rock fracture networks. Hydrogeol J. doi:10.1007/s10040-016-1441-8

Lukas T, Schiava D'Albano GG, Munjiza A (2014) Space decomposition based parallelization solutions for the combined finite-discrete element method in 2D. J Rock Mech Geotech Eng 6:607-615. doi:10. 1016/j.jrmge.2014.10.001

Luo S, Zhao Z, Peng H, Pu H (2016) The role of fracture surface roughness in macroscopic fluid flow and heat transfer in fractured rocks. Int J Rock Mech Min Sci 87:29-38. doi:10.1016/j.ijrmms.2016.05.006

Mahabadi OK, Lisjak A, Munjiza A, Grasselli G (2012) Y-Geo: a new combined finite-discrete element numerical code for geomechanical applications. Int J Geomech 153. doi:10.1061/(ASCE)GM.19435622.0000216

Matthäi SK, Belayneh M (2004) Fluid flow partitioning between fractures and a permeable rock matrix. Geophys Res Lett 31:L07602. doi: 10.1029/2003GL019027

Min K-B, Rutqvist J, Tsang C-F, Jing L (2004) Stress-dependent permeability of fractured rock masses: a numerical study. Int J Rock Mech Min Sci 41:1191-1210. doi:10.1016/j.ijrmms.2004.05.005

Munjiza A (2004) The combined finite-discrete element method. Wiley, London

Munjiza A, Andrews KRF (2000) Penalty function method for combined finite-discrete element systems comprising large number of separate bodies. Int J Numer Methods Eng 49:1377-1396. doi:10.1002/ 1097-0207(20001220)49:11<1377::AID-NME6>3.0.CO;2-B

Munjiza A, Andrews KRF, White JK (1999) Combined single and smeared crack model in combined finite-discrete element analysis. Int J Numer Methods Eng 44:41-57. doi:10.1002/(SICI)10970207(19990110)44:1<41::AID-NME487>3.0.CO;2-A

Munjiza A, Knight EE, Rougier E (2011) Computational mechanics of discontinua. Wiley, Chichester, UK

Munjiza A, Lei Z, Divic V, Peros B (2013) Fracture and fragmentation of thin shells using the combined finite-discrete element method. Int J Numer Methods Eng 95:478-498. doi:10.1002/nme.4511

Oda M (1985) Permeability tensor for discontinuous rock masses. Géotechnique 35:483-495. doi:10.1680/geot.1985.35.4.483

Olson JE (2003) Sublinear scaling of fracture aperture versus length: an exception or the rule? J Geophys Res 108:2413. doi:10.1029/ 2001JB000419

Olsson R, Barton N (2001) An improved model for hydromechanical coupling during shearing of rock joints. Int J Rock Mech Min Sci 38:317-329. doi:10.1016/S1365-1609(00)00079-4

Oron AP, Berkowitz B (1998) Flow in rock fractures: the local cubic law assumption reexamined. Water Resour Res 34:2811-2825. doi:10. 1029/98WR02285
Pollard DD, Segall P (1987) Theoretical displacements and stresses near fractures in rock: with applications to faults, joints, veins, dikes, and solution surfaces. In: Atkinson BK (ed) Fracture mechanics of rock. Academic, San Diego, pp 277-349

Renard P, de Marsily G (1997) Calculating equivalent permeability: a review. Adv Water Resour 20:253-278. doi:10.1016/S03091708(96)00050-4

Rougier E, Knight EE, Broome ST, Sussman AJ, Munjiza A (2014) Validation of a three-dimensional finite-discrete element method using experimental results of the split Hopkinson pressure bar test. Int J Rock Mech Min Sci 70:101-108. doi:10.1016/j.jirmms.2014.03.011

Rutqvist J, Stephansson O (2003) The role of hydromechanical coupling in fractured rock engineering. Hydrogeol J 11:7-40. doi:10.1007/ s10040-002-0241-5

Sanderson DJ, Zhang X (1999) Critical stress localization of flow associated with deformation of well-fractured rock masses, with implications for mineral deposits. In: Mccavvrey KJW, Lonergan L, Wilkinson JJ (eds) Fractures, fluid flow and mineralization. Geol Soc London Spec Pub 155:69-81

Sanderson DJ, Zhang X (2004) Stress controlled localisation of deformation and fluid flow in fractured rocks. In: Cosorove JW, Engelder T (eds) The initiation, propagation, and arrest of joints and other fractures. Geol Soc London Spec Pup 231:299-314

Thompson ME, Brown SR (1991) The effect of anisotropic surface roughness on flow and transport in fractures. J Geophys Res 96: 21923. doi:10.1029/91JB02252

Tsang C-F, Neretnieks I (1998) Flow channeling in heterogeneous fractured rocks. Rev Geophys 36:275-298. doi:10.1029/97RG03319

Wang X, Lei Q, Lonergan L, Jourde H, Gosselin O, Cosgrove J (2017) Heterogeneous fluid flow in fractured layered carbonates and its implication for generation of incipient karst. Advances in Water Resources

Warren JE, Root PJ (1963) The behavior of naturally fractured reservoirs. Soc Pet Eng J 3:245-255. doi:10.2118/426-PA

Willemse EJM, Pollard DD (1998) On the orientation and patterns of wing cracks and solution surfaces at the tips of a sliding flaw or fault. J Geophys Res 103:2427. doi:10.1029/97JB01587

Witherspoon PA, Wang JSY, Iwai K, Gale JE (1980) Validity of cubic law for fluid flow in a deformable rock fracture. Water Resour Res 16: 1016-1024. doi:10.1029/WR016i006p01016

Xiang J, Munjiza A, Latham J-P (2009a) Finite strain, finite rotation quadratic tetrahedral element for the combined finite-discrete element method. Int J Numer Methods Eng 79:946-978. doi:10.1002/nme.2599

Xiang J, Munjiza A, Latham J-P, Guises R (2009b) On the validation of DEM and FEM/DEM models in 2D and 3D. Eng Comput 26:673687. doi:10.1108/02644400910975469

Yeo IW, de Freitas MH, Zimmerman RW (1998) Effect of shear displacement on the aperture and permeability of a rock fracture. Int J Rock Mech Min Sci 35:1051-1070. doi:10.1016/S0148-9062(98)00165-X

Zhang X, Sanderson DJ (1996) Effects of stress on the two-dimensional permeability tensor of natural fracture networks. Geophys J Int 125: 912-924. doi:10.1111/j.1365-246X.1996.tb06034.x

Zhang X, Sanderson DJ, Harkness RM, Last NC (1996) Evaluation of the 2$\mathrm{D}$ permeability tensor for fractured rock masses. Int J Rock Mech Min Sci Geomech Abstr 33:17-37. doi:10.1016/0148-9062(95)00042-9

Zhao Z, Jing L, Neretnieks I, Moreno L (2011) Numerical modeling of stress effects on solute transport in fractured rocks. Comput Geotech 38:113-126. doi:10.1016/j.compgeo.2010.10.001

Zimmerman RW, Main I (2004) Hydromechanical behavior of fractured rocks. In: Gueguen Y, Bouteca M (eds) Mechanics of fluid-saturated rocks. Elsevier, London, pp 363-421

Zoback MD (2007) Reservoir geomechanics. Cambridge University Press, Cambridge 